\title{
Chapter 3 \\ Social and Emotional Learning: \\ From Conceptualization to Practical Application in a Global Context
}

\author{
Katharine E. Brush, Stephanie M. Jones, Rebecca Bailey, Bryan Nelson, \\ Natasha Raisch, and Emily Meland
}

\begin{abstract}
Social and emotional learning (SEL) is an effective way to promote positive learning, health, and wellbeing outcomes among children and youth, but the field lacks consensus about which skills and competencies are most important, what they should be called, and how they should be promoted and measured across diverse global contexts. SEL is also referred to by many names, often overlapping with life skills education (LSE) and other initiatives to improve learning, health, and developmental outcomes for children and youth. This chapter begins by describing SEL and its relationship to LSE and the United Nation's Sustainable Development Goals. It then showcases where clarity and cohesion do or do not exist within the field of SEL by exploring how SEL is conceptualized, measured, and promoted in different settings around the world. We draw on data collected over a series of research projects in which we applied a common coding system to SEL frameworks, programs, and measurement/assessment tools in order to identify areas of overlap and divergence between them. The chapter summarizes key findings from these projects while highlighting the need for deeper contextualization and localized research and development and concludes by discussing implications for research and practice.
\end{abstract}

Keywords Social and emotional learning · Culture and context · Interventions · Measurement/assessment tools · Frameworks

K. E. Brush $(\bowtie) \cdot$ S. M. Jones $\cdot$ R. Bailey $\cdot$ B. Nelson $\cdot$ N. Raisch $\cdot$ E. Meland Harvard Graduate School of Education, Cambridge, MA, USA e-mail: katharine_brush@gse.harvard.edu; stephanie_m_jones@gse.harvard.edu; rebecca_bailey@gse.harvard.edu; nraisch@gse.harvard.edu; bryan_nelson@mail.harvard.edu; emily_meland@gse.harvard.edu 


\section{Acronyms}

CASEL

EU NESET

IRC

LSE

MELQO MODEL

MESH

NGO

OECD

SEL

United Nations SDGs

UNESCO

UNICEF

USAID
Collaborative for Academic, Social, and Emotional Learning

European Union's Network of Experts working on the Social dimension of Education and Training

International Rescue Committee

Life skills education

Measurement of Early Learning Quality and Outcomes Measurement of Development and Early Learning

Mindsets, Essential Skills, and Habits

Non-governmental organization

Organisation for Economic Co-operation and Development Social and emotional learning

Sustainable Development Goals

United Nations Educational, Scientific and Cultural Organization

United Nations Children's Fund

United States Agency for International Development

\section{Introduction}

Children and youth require more than just academic and vocational skills to succeed in school, work, and life. Numerous studies have shown that social, emotional, behavioral, and character skills, knowledge, attitudes, and competencies - often collectively referred to as nonacademic skills and competencies - matter for many areas of development, including learning, health, and general wellbeing (e.g., Jones et al., 2015; Jones \& Kahn, 2017; Merrell \& Gueldner, 2010; Moffit et al., 2011). Moreover, these skills and competencies are essential to achieving international education and development goals, including developing responsible citizens, addressing poverty and conflict, ensuring quality and equitable education, and achieving global sustainability. However, while there is agreement about the importance of nonacademic skills, there remains a lack of consensus about which skills are most important, what they should be called, and how they should be promoted and measured - which has led many in the field to express concern about the lack of precision with which we discuss and measure them (Care et al., 2017; Engber, 2016; Gehlbach, 2015; Reeves \& Venator, 2014; Sánchez Puerta et al., 2016; Whitehurst, 2016; Zernike, 2016).

It is within this broad and somewhat contentious nonacademic domain that the fields of life skills education (LSE) and social and emotional learning (SEL) are situated. LSE has long been a common approach to promoting and reinforcing nonacademic skills and competencies in the international education and development sector. 
More recently, there has also been growing international interest in the separate but related field of SEL, with many governmental bodies, multilateral organizations, and international non-governmental organizations (NGOS) beginning to incorporate SEL concepts and programming into their work, either in coordination with or in parallel to LSE efforts. Reflecting the broader nonacademic field, SEL lacks clarity around how skills and competencies are conceptualized, defined, taught, and measured across diverse approaches. SEL is often treated as monolithic, but the frameworks used to guide SEL policy and practice, as well as the programs and measurement tools designed to promote and measure SEL skills, do not all include or target the same set of skills, nor do they use the same language to describe them, making it difficult to ensure alignment between SEL research, programming, and assessment.

This chapter addresses three major topics: (a) describing SEL and distinguishing it from LSE, (b) showcasing where clarity and cohesion do or do not exist within the field of SEL, and (c) discussing the implications for research and practice. To do so, the chapter first defines SEL, highlights its relevance to the field of international education and development and its role in supporting the United Nation's Sustainable Development Goals (SDGs), and distinguishes it conceptually from the field of LSE. Second, it lays out a major challenge facing SEL, describing how a lack of clarity and transparency in the field makes it difficult to accurately translate research into practice. This section introduces a coding system designed to respond to this challenge by acting as a "Rosetta Stone" for the field, identifying points of alignment and divergence across distinct yet related SEL frameworks, programs, and measures. It also explores issues related to the relevance and fit of SEL in settings outside of the United States. Finally, the third section of the chapter analyzes data from three projects that applied the coding system to SEL frameworks, programs, and measurement/assessment tools in order to better understand where alignment does or does not exist between the theoretical conceptualization and practical application of SEL. The chapter concludes by sharing the implications of these challenges for research and practice.

\section{What Is Social and Emotional Learning?}

Broadly speaking, social and emotional learning, or SEL, refers to the process through which individuals learn and apply a set of social, emotional, and related nonacademic skills, attitudes, behaviors, and values that help direct their thoughts, feelings, and actions in ways that enable them to succeed in school, work, and life (Jones et al., 2017). As we describe in this chapter, there are many ways of thinking about and categorizing specific SEL skills and competencies, ${ }^{1}$ but in general SEL

\footnotetext{
${ }^{1}$ There are many different terms used to describe the different constructs and components that fall under SEL, LSE, and other related fields (e.g., skills, competencies, behaviors, attitudes, beliefs, values, knowledge, etc.). For the purposes of this chapter, we use the two terms "skills and competencies." Both a skill and a competency refer to what one is able to do: Skills are abilities acquired
} 
tends to encompass some combination of cognitive, social, and emotional skills and competencies (Aspen Commission, 2019). For example, cognitive skills and competencies enable children to manage their thoughts, feelings, and behavior toward the attainment of a goal; emotional skills and competencies enable children to identify, understand, and manage their own feelings as well as relate to the emotions of others through empathy and perspective-taking; and social skills and competencies enable children to build and maintain healthy relationships, resolve conflicts, and work and play well with others (Jones \& Bouffard, 2012). Importantly, but oftentimes overlooked in the field of SEL, these skills and competencies are also accompanied by a belief ecology: a set of beliefs, values, and attitudes - ways of viewing and understanding ourselves and the world around us - that are based on our unique combination of knowledge, skills, and dispositions and which serve as an internal guide for driving and directing our behavior (Aspen Commission, 2019). This belief ecology not only influences the development of the skills and competencies included in the cognitive, social, and emotional domains, but also the ultimate purpose and end to which one puts those skills to use (e.g., whether we use strong perspectivetaking skills to empathize vs. harm).

Research demonstrates that social and emotional skills and competencies are malleable and teachable (Jones \& Kahn, 2017) and can be successfully developed and promoted through high-quality SEL programming (Durlak et al., 2011; Sklad et al., 2012; Taylor et al., 2017; Wiglesworth et al., 2016), particularly in educational settings, both formal and informal. Research also suggests that SEL may be particularly relevant for children and youth who face poverty, violence, and discrimination around the world (Inter-Agency Network for Education in Emergencies (INEE), 2016; Alexander et al., 2010), as children's social-emotional development is particularly sensitive to the negative effects of stress and trauma (Evans \& Kim, 2013; Noble et al., 2005; Raver et al., 2013). Importantly, SEL programs also tend to have the greatest impact on students who face the greatest number of risks, including those with lower socio-economic status and those who enter school behind their peers either academically or behaviorally (Bailey et al., 2019; Jones et al., 2011).

But it is important to highlight that high-quality SEL programming and assessment is about more than just targeting, teaching, and measuring skills and competencies. Social-emotional development does not occur in a vacuum; instead, it is deeply influenced by a variety of developmental and contextual factors including experiences, environments, and relationships, as well as the sociocultural norms and the political and economic realities of the settings in which people learn, play, and grow (Jones et al., 2017). The most effective SEL efforts are therefore sensitive to how skills and competencies are being developed and deployed across home, school, and community settings, and seek to provide safe and supportive learning

through training and practice and competencies are the application of those skills to specific tasks in ways informed by one's knowledge, beliefs, and values. For example, perspective-taking is a skill and the ability to use perspective-taking to navigate social situations effectively is a competency. 
environments, build teacher skills and capacity, and involve families and communities in decision-making and learning (Jones et al., 2018).

\section{Relevance of Social and Emotional Learning to International Education and Development Goals}

In the international education and development sector, social and emotional skills and competencies are important for both individual and national self-reliance, prosperity, and harmony (United States Agency for International Development (USAID), 2019). First, skills like responsible decision-making, problem-solving, goal-setting, peaceful conflict resolution, and empathy enable individuals to make the most of the resources and opportunities available to them, advocate for positive social and political change, and decrease prejudice and conflict. Second, SEL has an important role to play in achieving the United Nation's SDGs, particularly SDG 4: "ensure inclusive and equitable education and promote lifelong learning opportunities for all," by providing students with the skills, competencies, and learning environments they need to be effective and engaged learners. Decades of research in human development suggest that social, emotional, and cognitive development are integral to mastering academic content and developing learning behaviors that support students to reach academic benchmarks (Jones \& Zigler, 2002; Immordino-Yang \& Damasio, 2007; Immordino-Yang, 2011). SEL efforts have also been linked to safer, betterfunctioning schools and classrooms characterized by positive relationships and a supportive culture and climate (Jones \& Bouffard, 2012; Merritt et al., 2012; Okonofua et al., 2016a, b; Schonert-Reichl, 2017).

As highlighted in a recent policy brief by USAID (2019), SEL and other "soft skills" efforts can support educational access and quality in international settings by improving academic outcomes, promoting safety and inclusivity, mitigating the negative impact of trauma on learning and development, and building teachers' capacity to effectively support all students - including even the most marginalized learners, such as girls, children with disabilities, and children from racial/ethnic minority groups. For example, a recent impact evaluation in the Democratic Republic of Congo found that teacher professional development paired with an SEL curriculum improved student perceptions of their school as safe and supportive and led to improvements in their literacy and numeracy skills (Torrente et al., 2019). The same USAID brief also suggests that education programs that intentionally incorporate SEL may have the potential to help foster inclusivity at school by removing institutional barriers like inequitable discipline, school management, and instructional practices that prevent marginalized learners from accessing or participating fully in learning opportunities. 


\section{Distinguishing Social and Emotional Learning from Life Skills Education}

SEL and LSE are at times conflated or used interchangeably as umbrella terms that refer to the same broad and general set of nonacademic skills and competencies, erasing important differences in how they are conceptualized and operationalized across the two fields. Other terms and disciplines often blended or conflated with SEL and LSE include twenty-first century learning, character and citizenship education, psychosocial supports, conflict resolution and peace education, employability skills, and youth development, to name just a few. In other instances, SEL is seen as a sub-group of LSE. This is a tempting assessment to make, as LSE does incorporate a focus on social and emotional skills and competencies; however, SEL as a field is its own entity, with its own research tradition, focus, goals, terminology, and desired outcomes that do not necessarily always align with those of LSE.

We conceptualize the relationship between LSE and SEL in the following way: The nonacademic domain represents a broad area of research and practice that encompasses an array of separate but related fields, including SEL and LSE, among many others. Importantly, LSE and SEL are rooted in different disciplines - or sets of knowledge and research traditions - that influence which skills and competencies they deem important and for whom, how they think about and organize those skills and competencies, and even what they call them. The field of SEL, for example, is grounded in developmental psychology and prevention science and traditionally focuses on elementary and primary school-age children, primarily in schools or other educational settings, although its use in secondary school and out-of-schooltime settings is growing. Accordingly, SEL efforts typically seek to target some combination of social, emotional, and self-regulation skills and competencies shown to impact school readiness, academic achievement, and classroom culture/ climate in ways that predict a variety of longer-term positive outcomes related to school, employment, health, and wellbeing. And importantly, most of the literature on which SEL is based comes from the United States, with only small - albeit growing - number of rigorous SEL studies conducted outside of Western contexts.

LSE, on the other hand, is in some ways a conglomeration of multiple disciplines and research traditions. While LSE has its origins in health-related prevention and education contexts with a focus on providing adolescents and young adults with the knowledge and skills required to make healthy choices related to drugs and alcohol, violence, and sexual/reproductive health, over the years that focus has expanded to incorporate additional concentration on the technical and vocational skills required for employment, as well as the empowerment of women and girls. Consequently, LSE tends to target skills/competencies and use terminology more appropriate for adolescent development, and frequently builds social and emotional skills and competencies alongside or in the context of health, parenting, vocational, and other related programming. Therefore, while the fields of SEL and LSE target similar nonacademic skills and competencies and overlap in many ways, they are not the 
same, and caution should be exercised when using the terms interchangeably or trying to fit one field under the other.

While the fields are conceptually separate, there remain many opportunities to learn and share best practices across them. Many organizations currently focus on either SEL or LSE, or silo their efforts in each area with separate initiatives for each, but it is true that both fields have a strong focus on social-emotional development and outcomes and there may be value in intentionally coordinated or combined approaches to SEL and LSE that are mutually reinforcing rather than separate or redundant. For example, coordinated SEL and LSE efforts can provide opportunities for social-emotional development across the age span, beginning with SEL in the early years and transitioning or broadening to LSE as students age. Just as SEL programs looking to expand into secondary school could learn from LSE, organizations engaged in life skills programming could benefit from a solid foundation in SEL, which would enable them to build foundational social and emotional skills and competencies with younger children, setting them up for later success as programming expands into other areas of LSE that are more developmentally appropriate for older youth, such as labor market skills and more complex nonacademic skills and competencies related to identity, agency, and empowerment.

\section{Complexity in the Field of Social and Emotional Learning}

\section{A Lack of Consensus, Clarity, and Precision}

Despite the growing popularity and promise of SEL, there remains a lack of consensus about which social, emotional, and related skills and competencies are most important, what they should be called, and whether and how they relate to each other. Underlying this challenge, and in some ways compounding it, is the fact that major SEL stakeholders have put forth competing frameworks. Frameworks are designed to describe and organize skills/competencies in order to guide research, policy, and practice, but often differ from one another in a number of key ways. For example, they might (a) prioritize different skills, (b) organize them into different groups and hierarchies, or (c) use different or even conflicting terminology to describe similar sets of skills (Jones et al., 2019a). This diversity of focus and approach is not inherently a problem; frameworks are highly aligned with their specific purposes and objectives, making for a rich and vibrant field that offers a variety of options and approaches from which to choose based on the unique needs of a population or setting. However, when this type of complexity results in differing or conflicting terminology as it has for SEL, LSE, and related fields, it becomes difficult to communicate clearly about what is important and make decisions about the right strategies and approaches to use in practice.

In order to effectively translate research for practice, there must be a clear link between what research says about how the outcome of interest is related to a 
particular skill (the evidence, often distilled into frameworks), how that skill can be developed in children and youth (the program/strategy), and how to measure it to determine if the program or intervention efforts were successful (the evaluation). When there is terminological messiness, it can be difficult to see at face-value where SEL frameworks, values, programs and practices, and measures align. For example, SEL currently suffers from a problem known as the "jingle and jangle" effect: frameworks, programs, and measures often refer to the same skill or competency by different names, or alternatively, use the same name to refer to two conceptually distinct skills (Jones et al., 2016b; Reeves \& Venator, 2014), making it difficult to identify whether frameworks and terms are referring to similar or distinct concepts.

When working in diverse global contexts, it is also important to consider how various SEL skills and competencies are understood and valued among different cultures and communities. The way in which SEL skills and competencies are conceptualized, prioritized, defined, and displayed are highly tied to culture, or the shared norms, beliefs, customs, values, and behavioral standards of a society that shape the way people understand, interpret, and make meaning of their experiences (Gay, 2018). Culture plays an integral role in defining and guiding beliefs about which social and emotional skills and competencies are considered important or deemed acceptable, and for which individuals or groups. Moreover, behavioral expression of those skills and competencies - for instance, outward expressions of emotion and empathy - may also differ across contexts.

In general, there is limited research on SEL in diverse global contexts (CastroOlivo \& Merrell, 2012; Garner et al., 2014). Much of the research comes out of the United States or other high-income, Western countries, and as a result, many frameworks - even those developed for use outside of the U.S. - are based on literature from Western contexts and therefore reflect Western, Eurocentric values, beliefs, and terminology (Jones et al., 2019d; Jukes et al., 2018). The SEL concepts and terms used in Western frameworks and literature do not always align with the values and interests of different contexts and cultures (Jukes et al., 2018) and sometimes do not translate easily - or even exist at all - in other languages (Jones et al., 2019d). This has important implications for both programming and assessment in that not only must frameworks, interventions, and assessment tools be aligned to each other but they must also reflect culturally relevant competencies and be designed to describe, teach, and measure those competencies in ways that are appropriate and accurate for the context (Jones et al., 2020).

Without greater clarity and a mechanism for making connections between diverse perspectives and terminology, stakeholders may end up cherry-picking programs or measures that may or may not be aligned with each other, with the outcomes being targeted, or with the cultural context - and therefore risk missing, misunderstanding, or simply not achieving the intended effects. Jones et al. (2019c) have suggested that this type of misalignment may help explain some of the mixed findings that have plagued SEL program evaluations over the years. They point, for example, to a large-scale study conducted by the Social and Character Development (SACD) Research Consortium (2010) that revealed no overall differences in social-emotional outcomes for schools randomized to a variety of social and character development 
interventions versus those in the no-intervention condition. The study, however, used a general measurement battery to look at a mix of different program approaches rather than using measures aligned to the specific skills being targeted by each program. Several of the individual randomized control trials included in the broader SACD study did find positive outcomes, which Jones and colleagues suggest may be the result of using measurement tools more closely tied to those programs' theories of change.

\section{Responding to the Challenge: Explore SEL Website and Coding System}

Over the past 5 years, we have developed a coding system and set of online tools (Explore SEL) that serve as a "Rosetta Stone" for the broad nonacademic domain (Jones et al., 2019a). Much like how the Rosetta Stone enabled historians to discover connections between ancient alphabets, Explore SEL is designed to enable users to make sense of and navigate between different frameworks, programs, and measures in the nonacademic domain, regardless of differences in terminology. The basis of Explore SEL is a coding system that, when applied to frameworks, programs, and measures, can be used to identify related areas of focus across them, thus enabling comparisons based on how the terms, strategies, and items are defined and described, rather than what they are called or labeled. The coding system captures whether/when the various competencies described within each framework, program, and measurement tool align with 550+ common nonacademic skills and competencies (e.g., "identifies emotions in others") across 6 broad domains and 23 sub-domains, as presented in Table 3.1. ${ }^{2}$ Each domain represents a conceptual category of focus in the broader nonacademic domain and they are representative of the kinds of skill/competency areas seen across many different fields. Within each domain is a set of more specific sub-domains, and within those sub-domains are a list of yet more specific skills, competencies, behaviors, and beliefs related to that conceptual category of focus. It is important to note that this coding system is not intended to serve as its own framework or to fit all nonacademic fields into its structure; it is merely meant to serve as method of cutting through surface-level terminological differences to see where frameworks, programs, and measures in the nonacademic domain are focusing on similar skills and competencies.

\footnotetext{
${ }^{2}$ The coding system used for Explore SEL was derived from a comprehensive review of the literature on social, emotional, and related nonacademic skills and competencies that are linked to an array of positive outcomes. It has been updated and refined over the course of multiple projects to incorporate skills and competencies from across the broad nonacademic domain, including the fields of SEL, LSE, positive youth development, character education, virtues/values, twenty-first century skills, employability skills, citizenship education, personality, and more. The complete coding system can be found online at https://exploresel.gse.harvard.edu
} 
Table 3.1 Six broad domains of SEL

\begin{tabular}{|c|c|c|}
\hline Domain & Description & $\begin{array}{l}\text { Related } \\
\text { sub-domains }\end{array}$ \\
\hline Cognitive & $\begin{array}{l}\text { Skills required to successfully and efficiently direct behavior } \\
\text { toward the attainment of a goal. Skills in this domain are } \\
\text { involved in tasks that require you to concentrate and focus, } \\
\text { remember instructions, prioritize tasks, control impulses, set } \\
\text { and achieve goals, interpret and use information to make } \\
\text { decisions, and more. }\end{array}$ & $\begin{array}{l}\text { Attention Control, } \\
\text { Working Memory } \\
\text { and Planning } \\
\text { Skills, } \\
\text { Inhibitory Control, } \\
\text { Cognitive } \\
\text { Flexibility, } \\
\text { Critical Thinking }\end{array}$ \\
\hline Emotion & $\begin{array}{l}\text { Skills that help you recognize, express, and control your } \\
\text { emotions as well as understand and empathize with others. } \\
\text { Skills in this domain are important not only for managing } \\
\text { your own feelings and behavior, but also for interacting with } \\
\text { and responding to others in prosocial ways. }\end{array}$ & $\begin{array}{l}\text { Emotional } \\
\text { knowledge and } \\
\text { expression, } \\
\text { Emotional and } \\
\text { behavioral } \\
\text { regulation } \\
\text { Empathy/ } \\
\text { perspective-taking }\end{array}$ \\
\hline Social & $\begin{array}{l}\text { Skills that help you accurately interpret other people's } \\
\text { behavior, effectively navigate social situations, and interact } \\
\text { positively with others. Skills in this domain are required to } \\
\text { work collaboratively, solve social problems, build positive } \\
\text { relationships, and coexist peacefully with others. }\end{array}$ & $\begin{array}{l}\text { Understanding } \\
\text { Social Cues, } \\
\text { Conflict } \\
\text { Resolution/Social } \\
\text { Problem Solving, } \\
\text { Prosocial/ } \\
\text { Cooperative } \\
\text { Behavior } \\
\end{array}$ \\
\hline Values & $\begin{array}{l}\text { Skills, character traits/virtues, and habits that support you to } \\
\text { be a prosocial and productive member of a particular } \\
\text { community. This includes values like understanding, caring } \\
\text { about, and acting upon core ethical values; the desire to } \\
\text { perform to one's highest potential; an eager and thoughtful } \\
\text { approach to knowledge and learning; and the habits required } \\
\text { to live and work together with others as a friend, family } \\
\text { member, and citizen. }\end{array}$ & $\begin{array}{l}\text { Ethical Values, } \\
\text { Performance } \\
\text { Values, } \\
\text { Civic Values, } \\
\text { Intellectual Values }\end{array}$ \\
\hline Perspectives & $\begin{array}{l}\text { A person's perspective is how they view and approach the } \\
\text { world. It impacts how they see themselves, others, and their } \\
\text { own circumstances and influences how they interpret and } \\
\text { approach challenges in their daily life. A positive perspective } \\
\text { can help children and youth protect against and manage } \\
\text { negative feelings to successfully accomplish tasks and get } \\
\text { along with others. }\end{array}$ & $\begin{array}{l}\text { Gratitude, } \\
\text { Optimism, } \\
\text { Openness, } \\
\text { Enthusiasm/zest }\end{array}$ \\
\hline Identity & $\begin{array}{l}\text { Identity encompasses how people understand and perceive } \\
\text { themselves and their abilities. It includes knowledge and } \\
\text { beliefs about themselves, including their ability to learn and } \\
\text { grow. When a person feels good about themselves; sure of } \\
\text { their place in the world; and confident in their ability to } \\
\text { learn, grow, and overcome obstacles, it becomes easier to } \\
\text { cope with challenges and build positive relationships. }\end{array}$ & $\begin{array}{l}\text { Self-Knowledge, } \\
\text { Purpose, } \\
\text { Self-Efficacy/ } \\
\text { Growth Mindset, } \\
\text { Self-Esteem }\end{array}$ \\
\hline
\end{tabular}


Since the start of our work developing Explore SEL, we have applied the coding system to 40 frameworks, 25 programs, and 34 measures. ${ }^{3}$ The resulting database of coded frameworks, programs, and measurement/assessment tools can be used to make comparisons within and across these areas of SEL and related fields, highlighting areas of alignment or divergence. For example, some programs or measurement tools focus exclusively on conflict resolution, while others focus on empathy, mindfulness or executive function, and still others focus on character values like integrity or honesty. By identifying the focus or composition of specific programs, measurement tools, and frameworks, stakeholders can better understand the skills being targeted in each effort, can select appropriate measures for evaluation or monitoring, and can understand and contribute to the growing body of research in accurate ways. In this chapter, we use the data generated from these projects to explore how SEL is conceptualized in frameworks and operationalized in practice through programs and measurement/assessment tools.

\section{Comparing Frameworks, Programs, and Measures for Social and Emotional Learning}

One way to learn more about how skills and competencies are conceptualized and defined across the field of SEL is to look carefully at the frameworks that different organizations, programs, and funders use to guide policy and practice in these areas. Frameworks carry a great deal of weight and influence because they are used to distill ways of thinking and prioritizing in order to tell stakeholders what to aim for, or in other words, what outcomes we can or should expect from any program, strategy, or practice. In the case of SEL, this means the kinds of knowledge, skills, and attitudes we should look for in children and youth, and when we should expect to see them across development (Jones et al., 2019a). As one of the most common ways of communicating about and organizing SEL skills, frameworks are frequently used to guide an organization, program, or funder's approach to the domain. Consequently, they often drive which skills and outcomes are prioritized, addressed, and measured.

But how do frameworks actually get translated into practice across the field? An analysis of frameworks illustrates how social, emotional, and related nonacademic skills and competencies are defined and conceptualized in the field of SEL. Yet frameworks are aspirational - they merely represent a blueprint for the skills we can or should target in order to move the needle on desired outcomes. One way to better understand how SEL skills and competencies are operationalized in the field is to look more closely at SEL programs and measurement tools. Programs, curricula,

\footnotetext{
${ }^{3}$ The coding occurred as part of three separately funded research projects: The Explore SEL website (http://exploresel.gse.harvard.edu; Jones et al., 2020), the Navigating SEL Guide (Jones et al., 2017), and the Interagency Network for Education in Emergencies Quality and Equitable Learning Outcomes SEL Mapping Project (Jones et al., 2020)
} 
and measurement/assessment tools dictate which nonacademic skill/competency areas, or domains, are emphasized in practice, and whether they align with those outlined by guiding frameworks.

It is important to clearly understand the skill/competency areas, or domains, on which frameworks, programs, and measures focus, and to understand which programs and measures align best with specific frameworks - because as NGOs, schools, governments, and intergovernmental organizations around the world increasingly seek to integrate SEL into the fabric of learning environments, stakeholders need to know what has been shown to be effective in addressing important outcomes. Since SEL is often treated as an all-encompassing umbrella term, it is possible to assume that all SEL programs will target every skill outlined in SEL frameworks, that those skills will be the same across all frameworks and programs, and that all SEL measurement tools will be able to capture the impact and effectiveness of any SEL program. In reality, however, SEL programs and measures target a wide gamut of skills and competencies and vary in scope from a narrow or specific focus on one or a few domains to a broad emphasis on many different ones.

The ability to select programs and measures that align to specific needs or outcomes is critical for the field of SEL to be successful over time. By applying the Explore SEL coding system to SEL frameworks, programs, and measurement/ assessment tools, it is possible to identify which skill areas are typically targeted or emphasized in practice and identify the existing links or gaps between frameworks, programs, and measures.

\section{A Closer Look at SEL Frameworks}

Out of the current Explore SEL database of 40 coded frameworks, 10 have been designed specifically for the field of SEL and/or have a strong foundation in SEL research and intentionally incorporate skills and competencies identified in the literature on SEL, and it is these we have included in our analysis below. It should be noted that this is a relatively small sample of frameworks and therefore should not be considered a definitive representation of the SEL field, particularly given the growing number and variety of organizations that study and implement SEL programming around the world. However, this sample includes frameworks that represent the perspectives of many important and influential actors in the fields of SEL and international education and development, including the Collaborative for Academic, Social, and Emotional Learning (CASEL); the Organisation for Economic Cooperation and Development (OECD); the European Union (EU); International Rescue Committee (IRC); as well as the United Nations Children's Fund (UNICEF); the United Nations Educational, Scientific and Cultural Organization (UNESCO), the World Bank, and the Center for Universal of Education at Brookings Institution (as part of the Measuring Early Learning Quality and Outcomes, or MELQO, initiative). 
Of the 10 frameworks included in the sample, four were developed for use across multiple countries: OECD's social and emotional learning competencies, IRC's social and emotional competencies, the MELQO Measure of Development and Early Learning (MODEL) framework, and the EU's Network of Experts working on the Social dimension of Education and Training (NESET) framework. And while designed primarily with U.S. contexts in mind, the CASEL framework is also frequently cited as an influential guide and resource by organizations that develop social, emotional, and related nonacademic skills and competencies in countries around the world (Jones et al., 2019d). Another five frameworks were designed for use in specific country or local contexts: The Anchorage and Connecticut standards; Mindsets, Essential Skills, and Habits (MESH) framework; and the Transforming Education framework were developed for use in U.S. contexts and the Vision of the Haitian Child framework was designed to guide SEL work in Haiti. More information about each of these frameworks can be found online at the Explore SEL website (http://www.exploresel.gse.harvard.edu), which houses more detailed framework profiles and a set of visual tools for making direct comparisons between all 40 frameworks in the database.

\section{On Which Skills Do SEL Frameworks Focus?}

Table 3.2 shows each framework's general focus by making it clear which domains receive the most attention in that framework. The percentages in the table indicate how much emphasis each framework places on the six domains of our coding system based on how many codes from each (i.e., cognitive, emotion, social, values, perspectives, and identity; see Table 3.1 for detailed descriptions) were applied to the terms included in that framework. Please see the Explore SEL website for a more detailed description of how frameworks were coded.

Table 3.2 Percent breakdown of domain focus across SEL frameworks

\begin{tabular}{|c|c|c|c|c|c|c|}
\hline Framework & Cognitive & Emotion & Social & Values & Persp. & Identity \\
\hline Anchorage K-12 SEL Standards & $8 \%$ & $25 \%$ & $31 \%$ & $22 \%$ & $4 \%$ & $10 \%$ \\
\hline CASEL Framework for Systemic SEL & $20 \%$ & $23 \%$ & $28 \%$ & $20 \%$ & $3 \%$ & $8 \%$ \\
\hline Connecticut $K$-3 SEL Standards & $33 \%$ & $21 \%$ & $28 \%$ & $10 \%$ & $4 \%$ & $4 \%$ \\
\hline $\begin{array}{l}\text { EU NESET Framework for Social and } \\
\text { Emotional Education }\end{array}$ & $24 \%$ & $13 \%$ & $20 \%$ & $28 \%$ & $2 \%$ & $13 \%$ \\
\hline $\begin{array}{l}\text { IRC Social and Emotional Learning } \\
\text { Competencies }\end{array}$ & $28 \%$ & $39 \%$ & $17 \%$ & $11 \%$ & $6 \%$ & $0 \%$ \\
\hline MELQO MODEL Module & $38 \%$ & $31 \%$ & $27 \%$ & $4 \%$ & $0 \%$ & $0 \%$ \\
\hline MESH & $28 \%$ & $6 \%$ & $6 \%$ & $39 \%$ & $0 \%$ & $22 \%$ \\
\hline OECD SEL Framework & $21 \%$ & $14 \%$ & $21 \%$ & $33 \%$ & $7 \%$ & $2 \%$ \\
\hline Preparing Youth to Thrive & $20 \%$ & $27 \%$ & $7 \%$ & $47 \%$ & $0 \%$ & $0 \%$ \\
\hline $\begin{array}{l}\text { Vision of the Haitian Child in Society: } \\
\text { SEL Framework }\end{array}$ & $17 \%$ & $17 \%$ & $21 \%$ & $25 \%$ & $6 \%$ & $15 \%$ \\
\hline Average across all frameworks & $24 \%$ & $22 \%$ & $21 \%$ & $24 \%$ & $3 \%$ & $7 \%$ \\
\hline
\end{tabular}


As indicated by Table 3.2, there is considerable variability in the relative emphasis SEL frameworks place on each skill domain; however, all SEL frameworks include at least some focus on the cognitive, social, emotion, and values domains. When averaging across the entire sample, there tends to be a relatively balanced focus on the cognitive, social, emotion, and values domains $(24 \%, 21 \%, 22 \%$, and $24 \%$ respectively). This emphasis on the cognitive, social, and emotional domains aligns well with the literature on SEL, which tends to focus on the skills young children require to achieve academic success and function successfully in classroom and school environments: the need to be able to pay attention to the teacher and remember important instructions and rules, to regulate their emotions and behaviors, and to work and get along well with others. Interestingly, the MESH framework stands out as an outlier for including little focus on both the social and emotion domains (both 6\%), perhaps because it places a greater emphasis on intrapersonal competencies related to motivation, such as self-control and believing in one's ability to improve and succeed.

Interestingly, while values are often less explicitly discussed as being part of SEL work, some SEL frameworks get coded as having a strong emphasis on values. This may be because, to a certain extent, what is deemed a useful skill or appropriate behavior is tied to the social norms and values of a community. It may be difficult to define and describe their purpose without alluding to values in some way. For example, CASEL's definition of "social awareness" acknowledges the importance of understanding social and ethical norms for behavior and the OECD's framework includes a willingness to forgive as an important part of the "trust" required to collaborate or work well with others. However, SEL frameworks also show considerable variation in how much emphasis they place on the values domain $(\mathrm{SD}=13.53)$. The MELQO MODEL framework, for example, includes very little focus on values, perhaps because it is designed to guide measurement and therefore describes skills in ways that more closely resemble their empirical definitions without much additional elaboration.

SEL frameworks also rarely focus on the identity and perspectives domains. One reason for a general lack of focus on identity may be that skills and competencies that fall under the identity domain like self-efficacy, confidence, purpose, and agency are often areas that receive more attention in work with older children and youth as they explore who they are and what they want to do in the world. This may in fact be more the within the purview of the life skills field, which is often targeted more toward adolescents and young adults in health and vocational training programs, for whom these areas may be more developmentally and contextually appropriate. And even more so than identity, SEL frameworks include little to no emphasis on the perspectives domain: of the seven SEL frameworks in which it appears, it never makes up more than $7 \%$ of the codes applied. Attitudes and perspectives like gratitude, optimism, openness, and enthusiasm/zest rarely appear in the literature on SEL; those seeking to study, develop, and measure those particular constructs might see more emphasis on them in other corners of the nonacademic domain, in frameworks and literature that focus on personality traits, character education, virtues and values, mental health/psychosocial supports, or even mindfulness, which often incorporates aspects associated with openness into mindfulness practice (e.g., remaining open and receptive to the present moment). 


\section{A Closer Look at SEL Programs}

Recent meta-analyses have demonstrated that high-quality, evidence-based SEL programs produce positive outcomes for students, including improved behavior, attitudes, and academic performance (Durlak et al., 2011). There are many types of SEL programming available, including school-based prevention and intervention programs, schoolwide behavior management systems, and teacher-focused instructional and pedagogical practices. The most common approach involves comprehensive, scripted curricula that provide explicit SEL skill instruction through sequenced lessons (Jones et al., 2019b). But as mentioned earlier in this chapter, high-quality SEL is about more than just building skills; children's social-emotional development is highly influenced by their surroundings, from the immediate environments of their classrooms, homes, and communities to the larger socio-political forces operating around them. SEL programming is therefore most successful when it creates safe and supportive learning environments, supports the social-emotional competence of adults, engages caregivers and builds strong family-school-community partnerships, and provides opportunities to practice and apply SEL skills outside of regular classroom and school settings such as on the playground and at home (Jones et al., 2017). When implemented with fidelity, high-quality SEL programming has been shown to produce benefits for all children and youth, regardless of geographical setting (e.g., urban, suburban, rural) or socio-demographic background (Bridgeland et al., 2013; DePaoli et al., 2015; Durlak et al., 2011; Taylor et al., 2017).

At the same time, we know very little about what is "inside" SEL programs - the specific skills, strategies, and programmatic features that drive these positive outcomes. There are a great number of SEL programs available for schools and other educational organizations to choose from, and those programs vary widely in skill focus, teaching strategies, implementation supports, and general approach toward SEL. Some SEL programs primarily target emotion regulation and prosocial behavior, while others focus on executive function, growth mindset, character traits, or other skills. Some programs rely heavily on discussion as the primary teaching strategy, while others incorporate other instructional methods such as read-alouds, games, roleplays, music, and more. Programs also vary substantially in regard to their emphasis and material support for adult skill-building, community engagement, and other components beyond child-focused activities or curriculum.

\section{Which Skills and Competencies Do SEL Programs Build?}

This section focuses on a set of 15 coded programs. ${ }^{4}$ All self-identify as SEL programs and are designed to target a range of social, emotional, and nonacademic skills. Most of these programs are designed for use in formal elementary

\footnotetext{
${ }^{4}$ These 15 programs were selected for this analysis from the 25 nonacademic programs included in the Explore SEL database because they met the following criteria: (a) a self-reported focus on SEL (versus, for example, other fields like character education or positive youth development), and (b) at least one RCT showing positive impacts on social-emotional outcomes for students.
} 
school settings (approximately grades K-5 or ages 5-11) in the United States, but many have also been used in or provide adaptations for informal and out-ofschool-time settings such as afterschool programs, summer camps, mentoring organizations, sports programs, and more. As previously mentioned, while there are emerging efforts to develop and design SEL programs for other countries, cultures, and contexts around the world, most of these SEL programs originate from U.S. contexts, and in many cases SEL efforts abroad consist of adapting programs developed in the U.S. for use in other countries and settings (Jones et al., 2019d).

Table 3.3 displays the percentage of activities within a given program that target each domain in the Explore SEL coding system. Because a single program activity may target more than one domain, percentages across a single program may total more than $100 \%$. There is quite a bit of variation in the skills that SEL programs build. For example, RULER and Conscious Discipline have a strong focus on the emotion domain, while the Good Behavior Game does not include any activities that build emotion skills. Often when you examine programs more closely, reasons for these distinctions become clear. For example, RULER's main objective is to promote emotional literacy; Conscious Discipline's Feeling Buddies curriculum is focused on emotion regulation and teaching children to recognize, label, accept, and manage emotions; and the Good Behavior Game is designed to teach children to choose positive over disruptive classroom behaviors and therefore does not ever specifically delve into emotion-related skills or competencies. Yet, despite these clear differences, there is a tendency to think of all SEL programs as the same.

Similar to SEL frameworks, almost all programs include at least some activities that target the cognitive, emotion, social, and values domains while perspectives/identity are not included at all in many programs. On average, SEL programs focus most on the emotion and social domains, followed by the cognitive domain. Interestingly, while SEL frameworks tend to place a strong emphasis on the values domain, all but three SEL programs include fewer than $15 \%$ of activities that focus on values-related content. The three programs (Lions Quest, Too Good for Violence, and Positive Action) include character and/or health education components that are not as present in other SEL programs, which may in part account for their higher focus on skills and competencies in the values domain, like responsible and ethical decision-making. The overall greater emphasis on emotion and social skills within SEL programs may suggest that these skills are easier to observe, target, and promote in concrete ways, in contrast to values and perspectives, which tend to be slightly more ambiguous, personal, and perhaps in some cases even personality- or trait-based, which brings into question their malleability and responsiveness to intervention, as well as what it means to value certain ways of being over others. 
3 Social and Emotional Learning: From Conceptualization to Practical Application...

Table 3.3 Percentage of program activities that target each domain

\begin{tabular}{l|l|l|l|l|l}
\hline Program & Cognitive & Emotion & Social & Values & Persp./Identity \\
\hline The 4Rs Program & $12 \%$ & $27 \%$ & $43 \%$ & $14 \%$ & $0 \%$ \\
\hline Caring School Community & $8 \%$ & $33 \%$ & $78 \%$ & $13 \%$ & $0 \%$ \\
\hline Conscious Discipline & $14 \%$ & $75 \%$ & $54 \%$ & $4 \%$ & $7 \%$ \\
\hline $\begin{array}{l}\text { Competent Kids, Caring } \\
\text { Communities }\end{array}$ & $30 \%$ & $28 \%$ & $23 \%$ & $10 \%$ & $23 \%$ \\
\hline Good Behavior Game & $33 \%$ & $0 \%$ & $100 \%$ & $0 \%$ & $0 \%$ \\
\hline I Can Problem Solve & $65 \%$ & $65 \%$ & $55 \%$ & $3 \%$ & $0 \%$ \\
\hline Lions Quest & $18 \%$ & $23 \%$ & $60 \%$ & $19 \%$ & $7 \%$ \\
\hline MindUP & $44 \%$ & $28 \%$ & $18 \%$ & $4 \%$ & $19 \%$ \\
\hline PATHS & $30 \%$ & $75 \%$ & $59 \%$ & $12 \%$ & $2 \%$ \\
\hline Positive Action & $10 \%$ & $57 \%$ & $33 \%$ & $32 \%$ & $43 \%$ \\
\hline Responsive Classroom & $34 \%$ & $2 \%$ & $26 \%$ & $1 \%$ & $0 \%$ \\
\hline RULER & $10 \%$ & $94 \%$ & $51 \%$ & $3 \%$ & $0 \%$ \\
\hline Second Step & $40 \%$ & $52 \%$ & $49 \%$ & $7 \%$ & $1 \%$ \\
\hline Too Good for Violence & $12 \%$ & $53 \%$ & $67 \%$ & $42 \%$ & $5 \%$ \\
\hline WINGS & $16 \%$ & $41 \%$ & $36 \%$ & $9 \%$ & $3 \%$ \\
\hline Average across all programs & $25 \%$ & $44 \%$ & $50 \%$ & $12 \%$ & $7 \%$ \\
\hline
\end{tabular}

Note. Programs were coded before frameworks and measures using an earlier version of the coding system, which included only five domains instead of the current six: Cognitive, Emotion, Social, Character/Values, and Mindset. The Mindset domain in the original coding system roughly corresponds to a combination of the Perspectives and Identity domains in the current coding system, and it is therefore described that way in Table 3.3 for ease of comparison with the framework and measure data

\section{A Closer Look at Measures of Social-Emotional Development}

Measurement is currently one of the most challenging and contentious topics in the field of SEL (Duckworth \& Yeager, 2015). Being able to effectively measure SEL skills and evaluate SEL and LSE efforts is important for a variety of reasons, including progress tracking, course correction, and effective program evaluation that ultimately provides the field with valuable information about what is or is not working (Jones \& Barnes, 2018). But as with SEL programs, there are a wide variety of measurement/assessment tools available to choose from that target a range of different skills. For example, some tools have a narrow focus on a very specific skill or set of skills such as emotion knowledge, while others cast a wider or more general net across a variety of different skills. Due to the terminological complexity in the field, it is not always easy to determine where these differences exist in order to select a tool or combination of tools that target the skills one cares about (Jones et al., 2016a, b; Sánchez Puerta et al., 2016). These challenges are also of relevance to those working in the field of LSE; life skills programs with a strong emphasis on 
social-emotional outcomes seeking to identify appropriate measurement tools that target their desired outcomes can benefit from greater clarity and transparency. The goal is to find measures of social-emotional skills and competencies that are wellaligned with the skills and competencies targeted in program activities and articulated in their theory of change or guiding framework.

Moreover, SEL measures need to capture more than just individual skills and competencies. There is a tendency among existing measurement efforts to focus on assessing individual achievement; however, a relational approach to measurement one that takes into account the dynamic interaction between individuals and their environments - may be a better approach. To begin with, focusing solely on children's skills and competencies incorrectly implies that the goal of SEL is to "improve" or "fix" children (Jones \& Barnes, 2018). Secondly, decades of research make clear the important role environment and context play in children's socialemotional development (e.g., Bronfenbrenner \& Morris, 1998; Jones \& Molano, 2016; Milkie \& Warner, 2011; Osher et al., 2018; Sameroff, 2000). Without examining features of the setting that may be contributing to or hindering children's socialemotional development, we risk merely capturing children's responses to characteristics of the environment rather than anything meaningful about their overall social-emotional development. For example, students might display certain social-emotional skills in one setting but not in another because of differences in the resources - either emotional, relational, or material - available to them in any given moment. Considering context and features of the environment in assessment efforts is important for ensuring a more accurate picture of a child's functioning and development rather than just a snapshot of their response to the other children they are with, their relationship with their teacher, or the resources and materials available to them (Jones \& Barnes, 2018; Jones et al., 2016b).

\section{Which Skills and Competencies Do Measures of Social-Emotional Development Assess?}

The sample used in our analysis includes 35 measures selected in part for their focus on nonacademic constructs, appropriateness for children ages $0-18$, and use in diverse international contexts, including Africa, South Asia, Latin America, the Pacific Islands, Eastern Europe, Central Asia, and the Middle East. While not all of the 35 measures are designed specifically for use in the field of SEL, all assess social-emotional development in some capacity and were cited by stakeholders from around the world as tools commonly used to measure social and emotional skills and evaluate SEL programming. (Please see Jones et al., 2020 for more detailed selection criteria and additional background information for each measurement tool.)

As with SEL frameworks and programs, there is a great deal of variation in the emphasis different SEL measurement/assessment tools place on each domain, and as shown in Table 3.4, only nine tools capture skills across all six domains. For 
3 Social and Emotional Learning: From Conceptualization to Practical Application...

Table 3.4 Percent breakdown of domain focus across SEL measurement/assessment tools ${ }^{\mathrm{a}}$

\begin{tabular}{|c|c|c|c|c|c|c|}
\hline Measurement tool & Cognitive & Emotion & Social & Values & Persp. & Identity \\
\hline $\begin{array}{l}\text { Amal Alliance Local facilitator } \\
\text { assessment (Amal-Facilitator) }\end{array}$ & $0 \%$ & $36 \%$ & $16 \%$ & $40 \%$ & $0 \%$ & $8 \%$ \\
\hline $\begin{array}{l}\text { Amal Alliance parent assessment } \\
\text { (Amal-Parent) }\end{array}$ & $8 \%$ & $25 \%$ & $25 \%$ & $29 \%$ & $4 \%$ & $8 \%$ \\
\hline $\begin{array}{l}\text { Amal Alliance student assessment } \\
\text { (Amal-Student) }\end{array}$ & $13 \%$ & $17 \%$ & $17 \%$ & $17 \%$ & $13 \%$ & $22 \%$ \\
\hline Child Behavior Questionnaire (CBQ) & $29 \%$ & $14 \%$ & $14 \%$ & $7 \%$ & $14 \%$ & $21 \%$ \\
\hline The Children's Hope Scale & $25 \%$ & $0 \%$ & $0 \%$ & $25 \%$ & $25 \%$ & $25 \%$ \\
\hline $\begin{array}{l}\text { Caregiver Reported Early Childhood } \\
\text { Development Instruments long form } \\
\text { (CREDI-Long) }\end{array}$ & $46 \%$ & $23 \%$ & $23 \%$ & $8 \%$ & $0 \%$ & $0 \%$ \\
\hline $\begin{array}{l}\text { Caregiver Reported Early Childhood } \\
\text { Development Instruments short form } \\
\text { (CREDI-Short) }\end{array}$ & $43 \%$ & $29 \%$ & $14 \%$ & $14 \%$ & $0 \%$ & $0 \%$ \\
\hline $\begin{array}{l}\text { Child and Youth Resilience Measure } \\
\text { (CYRM-28) }\end{array}$ & $0 \%$ & $11 \%$ & $22 \%$ & $33 \%$ & $0 \%$ & $33 \%$ \\
\hline $\begin{array}{l}\text { Devereux Student Strengths Assessment } \\
\text { long form (DESSA-Long) }\end{array}$ & $15 \%$ & $10 \%$ & $23 \%$ & $36 \%$ & $10 \%$ & $5 \%$ \\
\hline $\begin{array}{l}\text { Devereux Student Strengths Assessment } \\
\text { short form (DESSA-mini) }\end{array}$ & $33 \%$ & $0 \%$ & $17 \%$ & $33 \%$ & $17 \%$ & $0 \%$ \\
\hline $\begin{array}{l}\text { EPOCH Measure of Adolescent } \\
\text { Wellbeing }(\text { EPOCH })\end{array}$ & $10 \%$ & $10 \%$ & $10 \%$ & $30 \%$ & $30 \%$ & $10 \%$ \\
\hline $\begin{array}{l}\text { Emotion Regulation Questionnaire } \\
(E R Q)\end{array}$ & $0 \%$ & $100 \%$ & $0 \%$ & $0 \%$ & $0 \%$ & $0 \%$ \\
\hline Short Grit Scale (Grit-S) & $50 \%$ & $0 \%$ & $0 \%$ & $50 \%$ & $0 \%$ & $0 \%$ \\
\hline General Self-Efficacy Scale (GSE) & $33 \%$ & $17 \%$ & $0 \%$ & $17 \%$ & $17 \%$ & $17 \%$ \\
\hline $\begin{array}{l}\text { Holistic Assessment of Learning and } \\
\text { Development Outcomes (HALDO) }\end{array}$ & $44 \%$ & $22 \%$ & $11 \%$ & $0 \%$ & $0 \%$ & $22 \%$ \\
\hline $\begin{array}{l}\text { International Civic and Citizenship } \\
\text { Study - Introduction to School (ICCS } \\
\text { School) }\end{array}$ & $11 \%$ & $0 \%$ & $33 \%$ & $44 \%$ & $0 \%$ & $11 \%$ \\
\hline $\begin{array}{l}\text { International Civic and Citizenship } \\
\text { Study - Introduction to Student (ICCS } \\
\text { Student) }\end{array}$ & $0 \%$ & $0 \%$ & $26 \%$ & $66 \%$ & $3 \%$ & $6 \%$ \\
\hline $\begin{array}{l}\text { International Development and Early } \\
\text { Learning Assessment (IDELA) }\end{array}$ & $32 \%$ & $26 \%$ & $16 \%$ & $16 \%$ & $0 \%$ & $11 \%$ \\
\hline $\begin{array}{l}\text { International Social and Emotional } \\
\text { Learning Assessment (ISELA) }\end{array}$ & $0 \%$ & $29 \%$ & $38 \%$ & $10 \%$ & $5 \%$ & $19 \%$ \\
\hline KIDCOPE & $18 \%$ & $24 \%$ & $35 \%$ & $0 \%$ & $12 \%$ & $12 \%$ \\
\hline $\begin{array}{l}\text { Malawi Development Assessment Tool } \\
(M D A T)\end{array}$ & $14 \%$ & $29 \%$ & $29 \%$ & $29 \%$ & $0 \%$ & $0 \%$ \\
\hline $\begin{array}{l}\text { MELQO Measurement of Development } \\
\text { and Early Learning direct assessment } \\
(M E L Q O M O D E L-D A)\end{array}$ & $75 \%$ & $25 \%$ & $0 \%$ & $0 \%$ & $0 \%$ & $0 \%$ \\
\hline
\end{tabular}


Table 3.4 (continued)

\begin{tabular}{|c|c|c|c|c|c|c|}
\hline Measurement tool & Cognitive & Emotion & Social & Values & Persp. & Identity \\
\hline $\begin{array}{l}\text { MELQO Measurement of Development } \\
\text { and Early Learning parent/caregiver } \\
\text { report (MELQO MODEL-P) }\end{array}$ & $33 \%$ & $25 \%$ & $8 \%$ & $33 \%$ & $0 \%$ & $0 \%$ \\
\hline $\begin{array}{l}\text { MELQO Measurement of Development } \\
\text { and Early Learning teacher report } \\
(M E L Q O M O D E L-T)\end{array}$ & $33 \%$ & $25 \%$ & $8 \%$ & $33 \%$ & $0 \%$ & $0 \%$ \\
\hline $\begin{array}{l}\text { Programme for International Student } \\
\text { Assessment for Development student } \\
\text { questionnaire (PISA-D) }\end{array}$ & $0 \%$ & $22 \%$ & $22 \%$ & $11 \%$ & $17 \%$ & $28 \%$ \\
\hline $\begin{array}{l}\text { Preschool Self-Regulation Assessment } \\
\text { assessor report (PSRA-AR) }\end{array}$ & $34 \%$ & $25 \%$ & $19 \%$ & $16 \%$ & $3 \%$ & $3 \%$ \\
\hline $\begin{array}{l}\text { Preschool Self-Regulation Assessment } \\
\text { direct assessment (PSRA-DA) }\end{array}$ & $71 \%$ & $0 \%$ & $29 \%$ & $0 \%$ & $0 \%$ & $0 \%$ \\
\hline $\begin{array}{l}\text { RTI International's Confidence and } \\
\text { Curiosity measure (RTI Tanzania-CC) }\end{array}$ & $0 \%$ & $0 \%$ & $17 \%$ & $50 \%$ & $0 \%$ & $33 \%$ \\
\hline $\begin{array}{l}\text { RTI International's Pilot Parent } \\
\text { Questionnaire for SEL Quantitative } \\
\text { Study in Tanzania (RTI Tanzania-P) }\end{array}$ & $23 \%$ & $8 \%$ & $21 \%$ & $41 \%$ & $5 \%$ & $3 \%$ \\
\hline $\begin{array}{l}\text { RTI International's Pilot Teacher } \\
\text { Questionnaire for SEL Qualitative Study } \\
\text { in Tanzania (RTI Tanzania-T) }\end{array}$ & $23 \%$ & $10 \%$ & $19 \%$ & $48 \%$ & $0 \%$ & $0 \%$ \\
\hline $\begin{array}{l}\text { Strengths and Difficulties Questionnaire } \\
(S D Q)\end{array}$ & $19 \%$ & $15 \%$ & $35 \%$ & $23 \%$ & $4 \%$ & $4 \%$ \\
\hline $\begin{array}{l}\text { Social Emotional Health Survey- } \\
\text { Secondary }(\text { SEHS-S) }\end{array}$ & $13 \%$ & $19 \%$ & $0 \%$ & $13 \%$ & $19 \%$ & $38 \%$ \\
\hline Social Provisions Scale (SPS) & $0 \%$ & $20 \%$ & $20 \%$ & $20 \%$ & $20 \%$ & $20 \%$ \\
\hline $\begin{array}{l}\text { YouthPower Action's Soft Skills Program } \\
\text { Staff Tool (YouthPower-S) }\end{array}$ & $21 \%$ & $16 \%$ & $26 \%$ & $26 \%$ & $0 \%$ & $11 \%$ \\
\hline $\begin{array}{l}\text { YouthPower Action's Softskills Youth Tool } \\
\text { (YouthPower-Y) }\end{array}$ & $15 \%$ & $21 \%$ & $21 \%$ & $24 \%$ & $3 \%$ & $18 \%$ \\
\hline Average across all tools & $22 \%$ & $19 \%$ & $18 \%$ & $24 \%$ & $6 \%$ & $11 \%$ \\
\hline
\end{tabular}

aplease see profiles in Jones et al. (2020) for more detailed information about each measurement tool

example, the Children's Behavior Questionnaire (CBQ; a survey that captures various aspects of temperament in children ages 3-7), focuses to varying degrees on all six domains, the Social Provisions Scale (SPS; an interview tool that captures the availability of social support that has been used with participants ages 9-20+) provides a balanced focus on five domains, and other tools like the Emotion Regulation Questionnaire (ERQ; an interview tool that measures a respondent's tendency to regulate their emotions through cognitive reappraisal and expressive suppression) and the Grit Scale Survey (GRIT-S; a self-report tool that captures perseverance and 
passion for long-term goals in youth ages 14+) have a narrow focus on only one or two domains. This suggests that organizations or programs seeking to assess child progress or evaluate programming may need to use a combination of tools to capture the full range of skills and competencies they care about.

That said, four tools in the sample that are designed specifically to capture socialemotional competence and SEL skills each include items that focus on at least five domains: the Devereaux Student Strengths Assessment (DESSA-long and DESSAmini; for grades K-8), the International Development and Early Learning Assessment (IDELA; for ages 3.5-6) and its version for older children International Social and Emotional Learning Assessment (ISELA; for ages 6-12), and the Holistic Assessment of Learning and Development Outcomes (HALDO; for ages 4-12 in conflict and crisis-affected contexts). While only a small sample, this may indicate that tools intentionally designed to assess general SEL competence may tend to have a broader scope than tools that focus on assessing more narrow constructs like grit or emotion regulation. Despite this variation, the tools in our sample tend to focus most on the cognitive and values domains, followed by the social and emotional domains. Similar to SEL frameworks and programs, the measurement/assessment tools in our sample focus least on the perspectives domain.

\section{How Do SEL Measures Take Context into Consideration?}

As noted above, SEL is about more than just child-focused competencies. To that end, we also analyzed the extent to which SEL measurement/assessment tools capture aspects of a child's environment that may hinder or promote the development and expression of SEL skills across five contextual factors: ecology, equity, health, safety, and adult support (see Table 3.5 for more detailed descriptions). This list of factors was decided upon based on a combination of: (a) desk research to determine contextual factors commonly considered by researchers in their analysis of measurement/assessment tools, and (b) factors that came up in the measurement/assessment tools in our sample during the coding process.

Findings from our coding for contextual factors confirm that most measurement tools focus on individual skills and competencies. Some measures like the International Civic and Citizenship Study (ICCS) and the Programme for International Student Assessment for Development (PISA) capture substantial information about features of the home/learning/community environment and aspects of a child's identity that impact their experiences (i.e. ecology, and to a lesser extent, equity), but a majority of tools capture little to no information about any of the contextual factors, suggesting there is an opportunity to expand SEL measurement efforts to capture richer information about children's relationship to their surroundings to paint a more complete picture of their social and emotional functioning. 
Table 3.5 Contextual factor descriptions

\begin{tabular}{|c|c|c|}
\hline Factor & Description & Example items ${ }^{a}$ \\
\hline Ecology & $\begin{array}{l}\text { The social networks, relationships, beliefs and } \\
\text { resources present in different areas of a child's life } \\
\text { (e.g., at home, in school, with friends, in the broader } \\
\text { community, etc.) that shape their daily experiences. }\end{array}$ & $\begin{array}{l}\text { Have you seen someone } \\
\text { reading at home? } \\
\text { Can you tell me the names } \\
\text { of your good friends? } \\
\text { Teachers have a positive } \\
\text { attitude towards school } \\
\text { Are there adults in your } \\
\text { community who care about } \\
\text { your health and safety? }\end{array}$ \\
\hline Equity & $\begin{array}{l}\text { Dimensions of a child's identity, background, and } \\
\text { experiences that may give them an advantage or } \\
\text { disadvantage in society (e.g., gender, race, socio- } \\
\text { economic status, immigration status, disability status, } \\
\text { language, etc.). }\end{array}$ & $\begin{array}{l}\text { What language(s) do you } \\
\text { speak at home? What } \\
\text { language do you learn at } \\
\text { school? } \\
\text { What is the highest level of } \\
\text { schooling completed by } \\
\text { your mother? } \\
\text { Do you have any concerns } \\
\text { about [child]'s } \\
\text { development? }\end{array}$ \\
\hline Health & $\begin{array}{l}\text { Aspects of a children's physical and mental health as } \\
\text { well as public health conditions (e.g., access to water, } \\
\text { sanitation, etc.). }\end{array}$ & $\begin{array}{l}\text { How often did you miss } \\
\text { school because you were } \\
\text { sick? } \\
\text { I cry for no reason. } \\
\text { Are you currently using } \\
\text { any method to delay } \\
\text { pregnancy? } \\
\text { Does your home have } \\
\text { running water? }\end{array}$ \\
\hline Safety & $\begin{array}{l}\text { A child's actual or perceived physical and psychosocial } \\
\text { safety (e.g., bullying, sexual and gender-based } \\
\text { violence, etc.). }\end{array}$ & $\begin{array}{l}\text { I feel unsafe walking to and } \\
\text { from school. } \\
\text { Teacher reported that } \\
\text { [child] was bullied by other } \\
\text { students. }\end{array}$ \\
\hline $\begin{array}{l}\text { Adult } \\
\text { support }\end{array}$ & $\begin{array}{l}\text { Support offered to adults (e.g., teachers, caregivers, } \\
\text { program staff, etc.) related to their own psychosocial or } \\
\text { social-emotional wellbeing or to supporting children's } \\
\text { psychosocial and social-emotional wellbeing. }\end{array}$ & $\begin{array}{l}\text { Teachers receive support in } \\
\text { positive classroom } \\
\text { management. } \\
\text { Teachers are trained to } \\
\text { detect cases of abuse or } \\
\text { trauma among their } \\
\text { students. }\end{array}$ \\
\hline
\end{tabular}

aPlease see Context Factor codebook in Jones et al. (2020) for detailed context factor descriptions and examples

\section{Discussion of Alignment Between SEL Frameworks, Programs, and Measures}

There are some notable points of consistency across SEL frameworks, programs, and measures. Every framework, measure, or program targeted social skills, although the extent to which they did so varied (Table 3.6). All three groups also 
Table 3.6 Average domain focus across frameworks, programs, and measures

\begin{tabular}{l|l|l|l|l|l|l}
\hline SEL resource & Cognitive & Emotion & Social & Values & Persp. & Identity \\
\hline Frameworks & $24 \%$ & $22 \%$ & $21 \%$ & $24 \%$ & $3 \%$ & $7 \%$ \\
\hline Programs & $25 \%$ & $44 \%$ & $50 \%$ & $12 \%$ & $7 \%$ a & - \\
\hline Measures & $22 \%$ & $19 \%$ & $18 \%$ & $24 \%$ & $6 \%$ & $11 \%$ \\
\hline
\end{tabular}

${ }^{a}$ Represents a combination of Perspectives and Identity domains

Note. Program percentages represent something slightly different than the framework and measurement/assessment tool percentages. The program percentages are simply the total percentage of activities in a program that received a code in a particular domain (e.g., all program activities that received a cognitive code $\div$ all program activities), whereas the framework and measure percentages represent how much emphasis is placed on that domain relative to the other domains (e.g., all cognitive codes applied to framework or measure $\div$ all codes from any domain applied to framework or measure). For this reason, we should be careful when making direct comparisons between these data; that said, we can use the data to see trends in skill emphasis and focus across frameworks, programs, and measurement/assessment tools and use that information to make general comparisons

rarely focused on the perspectives domain, indicating that fostering attitudes like optimism, enthusiasm, openness, and gratitude is not a priority in the field of SEL. However, while most frameworks and programs tended to include at least some focus on all six domains, only a quarter of measurement/assessment tools a focused on all six domains, and five $(\sim 15 \%)$ had a particularly narrow focus on only one, two, or three domains. This may indicate that many SEL measurement/assessment tools may be more targeted to a particular skill area than the typical SEL framework or program, and therefore cannot be used on their own to capture all relevant outcomes associated with a framework or program that targets a broader array of skills. Care must therefore be taken to carefully align measurement/assessment tools with framework definitions and program content, and in some cases multiple measures might be required to capture the full gamut of skills. Indeed, appropriate and psychometrically valid and reliable measures might not yet exist for all the key areas we need to capture, and therefore effort to build, contextualize, and test measures is important as well.

There are also notable differences in which domains received the greatest emphasis. SEL programs tended to place a greater emphasis on emotion skills than either frameworks or measures. Similarly, SEL frameworks and measures tended to emphasize values, but even while many programs targeted skills in that domain to some extent, they tended to do so sparingly. Programs also tended to focus on cognitive skills less frequently than do frameworks or measures. While it is certainly not necessary for every SEL program to target every domain, this may indicate there is an opportunity in the field to more intentionally address cognitive skills and values like executive function, compassion, and ethical decision-making that enable children to successfully marshal and direct those emotion and social skills more commonly targeted in programs toward academic and prosocial goals. While stakeholders and organizations may have different ideas and priorities about which skills are important to build, they should take care to select a program that includes the full array of skills they hope to promote as outlined in their framework or plan, whether 
that is a narrow focus on a particular set of skills and competencies, or a broader focus on a range of skills and competencies.

\section{Conclusion}

It is clear that SEL has a critical role to play in the success and wellbeing of young people around the world; however, there remain issues related to clarity, precision, and alignment, as well as cultural relevance and fit, that must be resolved in order to effectively deliver and assess social, emotional, and related skills and to achieve meaningful impacts for children and youth at scale. The wide array of skills and competencies included in, and the many fields that contribute to, the nonacademic domain can make it difficult to sort through and compare all of the research and guidance available in order to carefully align frameworks, programs, and measures in ways that cohesively promote and assess social-emotional development. As this chapter shows, there are many ways of thinking about what skills are important and which should be prioritized within the field of SEL, and there remain many unanswered questions about the relevance and fit of predominantly Western SEL frameworks, programming, and measures for diverse global contexts.

Careful alignment between frameworks, programs, and measures is therefore imperative so as not to overlook or misinterpret results in ways that give detractors reason to call into question the value of the nonacademic field as a whole (Dupuy et al., 2018; Jones et al., 2019c; Kwauk et al., 2018), and it is also becoming increasingly clear that contextualization - ideally in partnership with diverse local stakeholders (Jones et al., 2019d; Jukes et al., 2018) - is a critical step in developing or adapting nonacademic frameworks, programs, and measures to local contexts in order to effectively promote and measure skills in settings outside of the US and other Western countries.

While SEL and LSE are two distinct areas of study and we must be clear about where they overlap or diverge in order to coordinate approaches and select programming and measures that align with the needs, goals, and desired outcomes of a particular initiative, there exist opportunities for increased coordination and collaboration between them. The analyses in this chapter help clarify how SEL is being understood, taught, and measured by various SEL stakeholders in ways that support those working in the adjacent field of LSE to identify potential throughlines between the fields of SEL and LSE and identify trends in programming and measurement that can inform their own efforts to support the social-emotional development of youth. Progress in the field will occur when we begin to more intentionally develop and link frameworks to strategies, programs, and measures, and in ways that are sensitive and responsive to the local culture and context. Moving forward, the Explore SEL coding system and similar efforts to (a) increase clarity and precision in the field and (b) support careful and effective coordination and communication across nonacademic fields and organizations, will help ensure effective 
and precise translation of research into practice, and ultimately achieve greater results for children and youth around the world.

\title{
Funders \& Collaborators
}

\author{
Bill \& Melinda Gates Foundation \\ Echidna Giving \\ Einhorn Family Charitable Trust \\ Funders Collaborative for Innovative Measurement (FCIM) \\ Inter-agency Network for Education in Emergencies (INEE) \\ Porticus \\ Overdeck Family Foundation \\ Raikes Foundation \\ Wallace Foundation \\ William and Flora Hewlett Foundation
}

\section{References}

Alexander, J., Boothby, N., \& Wessells, M. (2010). Education and protection of children and youth affected by armed conflict: An essential link. In Protecting education from attack: A state of the art review (pp. 55-67).

Aspen Commission. (2019). From a Nation at Risk, to a Nation at Hope: Recommendations from the National Commission on Social, Emotional, and Academic Development. The Aspen Institute. http://nationathope.org/wp-content/uploads/2018_aspen_final-report_full_webversion.pdf

Bailey, R., Stickle, L., Brion-Meisels, G., \& Jones, S. M. (2019). Re-imagining social-emotional learning: Findings from a strategy-based approach. Phi Delta Kappan, 100(5), 53-58.

Bridgeland, J., Bruce, M., \& Hariharan, A. (2013). The missing piece: A national teacher survey on how social and emotional learning can empower children and transform schools. Collaborative for Academic, Social, and Emotional Learning. https://casel.org/wp-content/uploads/2016/01/ the-missing-piece.pdf

Bronfenbrenner, U., \& Morris, P. A. (1998). The ecology of developmental processes. In W. Damon \& R. M. Lerner (Eds.), Handbook of child psychology: Theoretical models of human development (pp. 993-1028). Wiley.

Care, E., Kim, H., Anderson, K., \& Gustafsson-Wright, E. (2017). Skills for a changing world: National perspectives and the global movement. Center for Universal Education at the Brookings Institution. https://youtheconomicopportunities.org/sites/default/files/ uploads/ resource/skills-for-a-changing-world.pdf

Castro-Olivo, S. M., \& Merrell, K. W. (2012). Validating cultural adaptations of a school-based social-emotional learning programme for use with Latino immigrant adolescents. Advances in School Mental Health Promotion, 5(2), 78-92.

DePaoli, J. L., Fox, J. H., Ingram, E. S., Maushard, M., Bridgeland, J. M., \& Balfanz, R. (2015). Building a Grad Nation: Progress and challenge in ending the high school dropout epidemic: Annual update 2015. https://files.eric.ed.gov/fulltext/ ED556759.pdf

Duckworth, A. L., \& Yeager, D. S. (2015). Measurement matters: Assessing personal qualities other than cognitive ability for educational purposes. Educational Researcher, 44(4), 237-251.

Dupuy, K., Bezu, S., Knudsen, A., Halvorsen, S., Kwauk, C., Braga, A., \& Kim, H. (2018). Life skills in non-formal contexts for adolescent girls in developing countries. CMI Report 
Number 5. Center for Universal Education at the Brookings Institution. https://www.cmi.no/ publications/6495-life-skills-in-non-formal-contexts-for-adolescent

Durlak, J. A., Weissberg, R. P., Dymnicki, A. B., Taylor, R. D., \& Schellinger, K. B. (2011). The impact of enhancing students' social and emotional learning: A meta-analysis of school-based universal interventions. Child Development, 82(1), 405-432.

Engber, D. (2016, May 8). Is grit really the key to success? Slate. http://www.slate.com/articles/ health_and_science/cover_story/2016/05/angela_duckworth_says_grit_is_the_key_to_success_in_work_and_life_is_this.html

Evans, G. W., \& Kim, P. (2013). Childhood poverty, chronic stress, self-regulation, and coping. Child Development Perspectives, 7(1), 43-48.

Explore SEL. http://exploresel.gse.harvard.edu/

Garner, P. W., Mahatmya, D., Brown, E. L., \& Vesely, C. K. (2014). Promoting desirable outcomes among culturally and ethnically diverse children in social emotional learning programs: A multilevel heuristic model. Educational Psychology Review, 26(1), 165-189.

Gay, G. (2018). Culturally responsive teaching: Theory, research, and practice. Teachers College Press.

Gehlbach, H. (2015, April 15). Name that baby: Why 'non-cognitive' factors need a new name. Education Week. http://blogs.edweek.org/edweek/rick_hess_straight_up/2015/04/noncognitive_factors_need_new_name.html

Immordino-Yang, M. H. (2011). Implications of affective and social neuroscience for educational theory. Educational Philosophy and Theory, 43(1), 98-103.

Immordino-Yang, M. H., \& Damasio, A. (2007). We feel, therefore we learn: The relevance of affective and social neuroscience to education. Mind, Brain, and Education, 1(1), 3-10.

Inter-Agency Network for Education in Emergencies (INEE). (2016). INEE background paper on psychosocial support and social and emotional learning for children and youth in emergency settings. Alves. https://inee.org/system/files/resources/ INEE_PSS-SEL_Background_Paper_ENG_v5.3.pdf

Jones, S. M., \& Barnes, S. P. (2018). What's missing in SEL measurement and assessment? Context. https://measuringsel.casel.org/whats-missing-in-sel-measurement-and-assessment-context/

Jones, S. M., \& Bouffard, S. M. (2012). Social and emotional learning in schools: From programs to strategies and commentaries. Social Policy Report, 26(4), 1-33.

Jones, S. M., \& Kahn, J. (2017). The evidence base for how we learn: Supporting students' social, emotional, and academic development. Aspen Institute. https://www.aspeninstitute.org/ publications/evidence-base-learn/

Jones, S. M., \& Molano, A. (2016). Seasonal and compositional effects of classroom aggression: A test of developmental-contextual models. Journal of Cognitive Education and Psychology, $15(2), 225-247$.

Jones, S. M., \& Zigler, E. (2002). The mozart effect: Not learning from history. Journal of Applied Developmental Psychology, 23(3), 355-372.

Jones, S. M., Brown, J. L., \& Aber, J. L. (2011). Two-year impacts of a universal school-based social-emotional and literacy intervention: An experiment in translational developmental research. Child Development, 82(2), 533-554.

Jones, D. E., Greenberg, M., \& Crowley, M. (2015). Early social-emotional functioning and public health: The relationship between kindergarten social competence and future wellness. American Journal of Public Health, 105(11), 2283-2290.

Jones, S. M., Bailey, R., Barnes, S. P., \& Partee, A. (2016a). Executive Function Mapping Project: Untangling the terms and skills related to executive function and self-Regulation in early childhood. OPRE Report \#2016-88, Washington, DC: Office of Planning, Research and Evaluation, Administration for Children and Families, U.S. Department of Health and Human Services. https://www.acf.hhs.gov/sites/default/files/opre/efmapping_report_101416_final_508.pdf

Jones, S. M., Zaslow, M., Darling-Churchill, K. E., \& Halle, T. G. (2016b). Assessing early childhood social and emotional development: Key conceptual and measurement issues. Journal of Applied Developmental Psychology, 45, 42-48. 
Jones, S. M., Brush, K. E., Bailey, R., Brion-Meisels, G., McIntyre, J., Kahn, J., Nelson, B., \& Stickle, L. (2017). Navigating SEL from the inside out: Looking inside \& across 25 leading SEL programs: A practical resource for schools and OST providers (elementary school focus). Wallace Foundation. https://www.wallacefoundation.org/knowledge-center/Documents/ Navigating-Social-and-Emotional-Learning-from-the-Inside-Out.pdf

Jones, S. M., Bailey, R., Brush, K. E., \& Kahn, J. (2018). Preparing for effective SEL implementation. https://www.wallacefoundation.org/knowledge-center/Documents/Preparing-forEffective-SEL-Implementation.pdf

Jones, S. M., Bailey, R., Brush, K. E., \& Nelson, B. (2019a). Introduction to the Taxonomy Project: Tools for selecting \& aligning SEL frameworks. https://measuringsel.casel.org/wp-content/ uploads/2019/02/Frameworks-C.1.pdf

Jones, S., Bailey, R., \& Kahn, J. (2019b). The science and practice of social and emotional learning: Implications for state policymaking. State Education Standard, 19(1), 18-24.

Jones, S. M., Bailey, R., Kahn, J. \& Barnes, S. P. (2019c). Social-emotional learning: What it is, what it isn't, and what we know. Education Next. https://www.educationnext.org/ social-emotional-learning-isnt-know/

Jones, S. M., Bailey, R., Meland, E., Brush, K. E., \& Nelson, B. (2019d). Integrating international frameworks into the taxonomy project: A report for Echidna Giving. Echidna Giving.

Jones, S. M., Bailey, R., Temko, S., Donaher, M., Raisch, N., \& Ramirez, T. (2020). SEL and PSS measurement and assessment tools in education in emergencies: Identifying, analyzing, and mapping tools to global guidance documents. Inter-Agency Network for Education in Emergencies (INEE).

Jukes, M., Gabrieli, P., Mgonda, N. L., Nsolezi, F., Jeremiah, G., Tibenda, J., \& Bub, K. L. (2018). "Respect is an investment": Community perceptions of social and emotional competencies in early childhood from Mtwara, Tanzania. Global Education Review, 5(2), 160-188.

Kwauk, C., Braga, A., Kim, H., Dupuy, K., Bezu, S., \& Knudsen, A. (2018). Non-formal girls'life skills programming: Implications for policy and practice. Chr. Michelsen Institute. https://files. eric.ed.gov/fulltext/ED586317.pdf

Merrell, K. W., \& Gueldner, B. A. (2010). Social and emotional learning in the classroom: Promoting mental health and academic success. The Guilford Press.

Merritt, E. G., Wanless, S. B., Rimm-Kaufman, S. E., Cameron, C., \& Peugh, J. L. (2012). The contribution of teachers' emotional support to children's social behaviors and self-regulatory skills in first grade. School Psychology Review, 41(2), 141.

Milkie, M. A., \& Warner, C. H. (2011). Classroom learning environments and the mental health of first grade children. Journal of Health and Social Behavior, 52(1), 4-22.

Moffitt, T. E., Arseneault, L., Belsky, D., Dickson, N., Hancox, R. J., Harrington, H., Houts, R., Poulton, R., Roberts, B. W., Ross, S., Sears, M. R., Thomson, W. M., \& Caspi, A. (2011). A gradient of childhood self-control predicts health, wealth, and public safety. Proceedings of the National Academy of Sciences, 108(7), 2693-2698.

Noble, K. G., Norman, M. F., \& Farah, M. J. (2005). Neurocognitive correlates of socioeconomic status in kindergarten children. Developmental Science, 8(1), 74-87.

Okonofua, J. A., Paunesku, D., \& Walton, G. M. (2016a). Brief intervention to encourage empathic discipline cuts suspension rates in half among adolescents. Proceedings of the National Academy of Sciences, 113(19), 5221-5226.

Okonofua, J. A., Walton, G. M., \& Eberhardt, J. L. (2016b). A vicious cycle: A social-psychological account of extreme racial disparities in school discipline. Perspectives on Psychological Science, 11(3), 381-398.

Osher, D., Cantor, P., Berg, J., Steyer, L., \& Rose, T. (2018). Drivers of human development: How relationships and context shape learning and development. Applied Developmental Science, $1-31$. 
Raver, C. C., Blair, C., \& Willoughby, M. (2013). Poverty as a predictor of 4-year-olds' executive function: New perspectives on models of differential susceptibility. Developmental Psychology, 49(2), 292-304.

Reeves, R. V., \& Venator, J. (2014, December 19). Jingle-jangle fallacies for non-cognitive factors. Brookings Institution. http://www.brookings.edu/blogs/social-mobilitymemos/ posts/2014/12/19-jingle-jangle-fallacies-noncognitive-factors-reeves

Sameroff, A. J. (2000). Developmental systems and psychopathology. Development and Psychopathology, 12(3), 297-312.

Sánchez Puerta, M. L., Valerio, A., \& Bernal, M. G. (2016). Taking stock of programs to develop socioemotional skills: A systematic review of program evidence (English). Directions in development paper. World Bank Group. http://documents.worldbank.org/curated/ en/249661470373828160/Taking-stock-of-programs-to-develop-socioemotional-skills-asystematic-review-of-program-evidence

Schonert-Reichl, K. A. (2017). Social and emotional learning and teachers. The Future of Children, 27(1), 137-155.

Sklad, M., Diekstra, R., De Ritter, M., Ben, J., \& Gravesteijn, C. (2012). Effectiveness of schoolbased universal social, emotional, and behavioral programs. Do they enhance students' development in the area of skill, behavior, and adjustment? Psychology in the Schools, 49, 892-909.

Social and Character Development (SACD) Research Consortium. (2010). Efficacy of schoolwide programs to promote social and character development and reduce problem behavior in elementary school children (NCER 2011-2001). National Center for Education Research, Institute of Education Sciences, U.S. Department of Education.

Taylor, R., Oberle, E., Durlak, J. A., \& Weissberg, R. P. (2017). Promoting positive youth development through school-based social and emotional learning interventions: A meta-analysis of follow-up effects. Child Development, 88, 1156-1171.

Torrente, C., Aber, J. L., Starkey, L., Johnston, B., Shivshanker, A., Weisenhorn, N., Annan, J., Seidman, E., Wolf, S., \& Tubbs Dolan, C. (2019). Improving primary education in the Democratic Republic of the Congo: End-line results of a cluster-randomized wait-list controlled trial of Learning in a Healing Classroom. Journal of Research on Educational Effectiveness, 12(3), 1-34.

Whitehurst, G. J. (2016). Hard thinking on soft skills. Brookings Institution. http://www.brookings.edu/research/reports/2016/03/24-hard-thinking-soft-skills-whitehurst

Wiglesworth, M., Lendrum, A., Oldfield, J., Scott, A., ten Bokkel, I., Tate, K., \& Emery, C. (2016). The impact of trial stage, developer involvement and international transferability on universal social and emotional learning programme outcomes: A meta-analysis. Cambridge Journal of Education, 46, 347-376.

Zernike, K. (2016, February 29). Testing for joy and grit? Schools nationwide push to measure students' emotional skills. The New York Times. http://www.nytimes.com/2016/03/01/us/testingfor-joy-and-grit-schools-nationwide-push-tomeasure-students-emotional-skills.html?version= meter+at $+2 \&$ module=meterLinks $\&$ pgtype $=$ article $\&$ content $I d=\&$ mediaId $=\&$ referrer $=\&$ priorit $\mathrm{y}=$ true \&action $=$ click\&contentCollecti on= 
Open Access This chapter is licensed under the terms of the Creative Commons Attribution 4.0 International License (http://creativecommons.org/licenses/by/4.0/), which permits use, sharing, adaptation, distribution and reproduction in any medium or format, as long as you give appropriate credit to the original author(s) and the source, provide a link to the Creative Commons license and indicate if changes were made.

The images or other third party material in this chapter are included in the chapter's Creative Commons license, unless indicated otherwise in a credit line to the material. If material is not included in the chapter's Creative Commons license and your intended use is not permitted by statutory regulation or exceeds the permitted use, you will need to obtain permission directly from the copyright holder. 